\title{
Endoscopic management of stent displacement after pancreatic pseudocyst drainage
}

A 50-year-old man who had experienced acute alcoholic pancreatitis 2 years earlier presented with abdominal pain. An abdominal computed tomography (CT) scan revealed a pseudocyst, $16 \times 8 \mathrm{~cm}$ in size, in the pancreatic tail ( $>$ Fig. 1). After multidisciplinary discussion, the patient was referred for endoscopic pseudocyst drainage.

Transgastric puncture of the pseudocyst was performed using a 19-gauge fineneedle aspiration needle, under endoscopic ultrasound (EUS) guidance. A 0.035-inch guidewire was advanced through the needle and the tract was dilated to $6 \mathrm{~mm}$. A fully covered doubleflanged metal stent $(40 \times 14 \mathrm{~mm})$ was then deployed across the tract under endoscopic, EUS, and fluoroscopic guidance. The deployment was complicated by complete intracystic migration of the stent. We decided to place a fully covered biliary metal stent $(60 \times 10 \mathrm{~mm})$ in an attempt to save the performed cystogastrostomy, and planned to retrieve the migrated stent at a later time. The patient was discharged with no symptoms. The patient was readmitted to our department 1 week later with fever and upper abdominal pain. Abdominal CT scan showed complete migration of the two stents into the pseudocyst cavity $(12 \times 6 \mathrm{~cm})$ (> Fig. 2$)$.

Under endoscopic, EUS, and fluoroscopic guidance, we placed another fully covered double-flanged metal stent (40x $14 \mathrm{~mm}$ ) through the patent cystogastrostomy ( $\triangleright$ Fig.3). The two intracystic migrated stents were then removed through the third stent using a foreign body forceps. Effective drainage of the pseudocyst was observed and the patient became asymptomatic ( $\triangleright$ Video 1 ). At follow-up 1 month later, after an abdominal CT scan showed complete resolution of the pseudocyst (> Fig.4), the stent was removed endoscopically (> Fig.5).

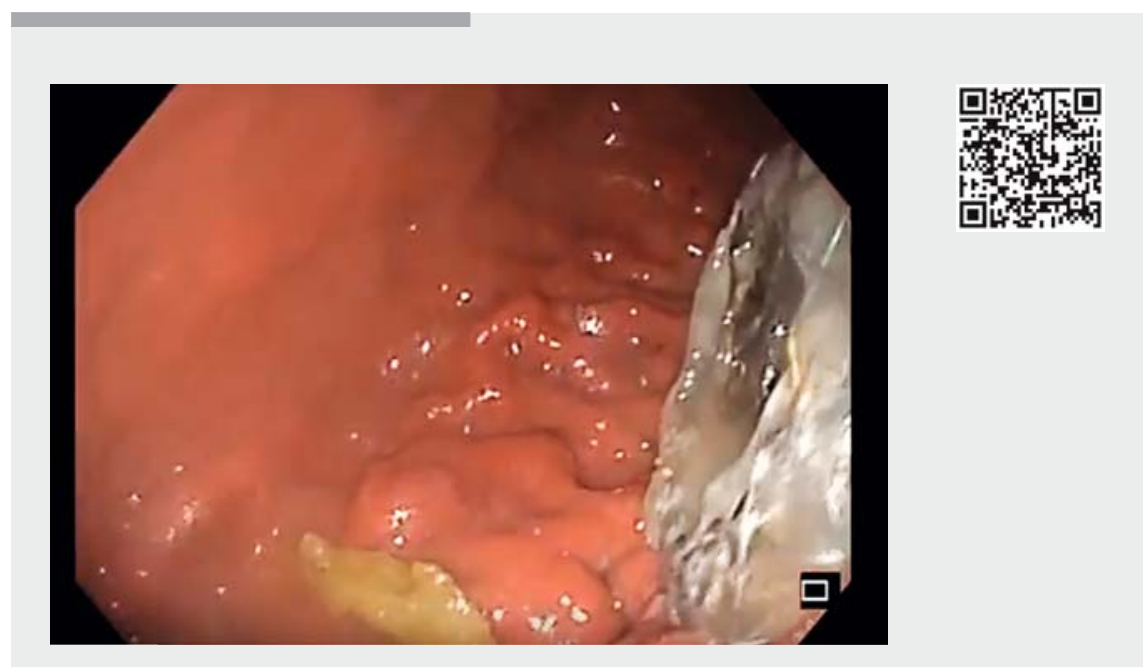

$\checkmark$ Video 1 Endoscopic management of stent displacement after pancreatic pseudocyst drainage. 1) View of the intragastric portion of double-flanged metal stent. 2) Access to the cystic cavity through the double-flanged metal stent. 3) View of the two intracystic migrated stents. 4) Removal of the biliary and double-flanged metal stents.

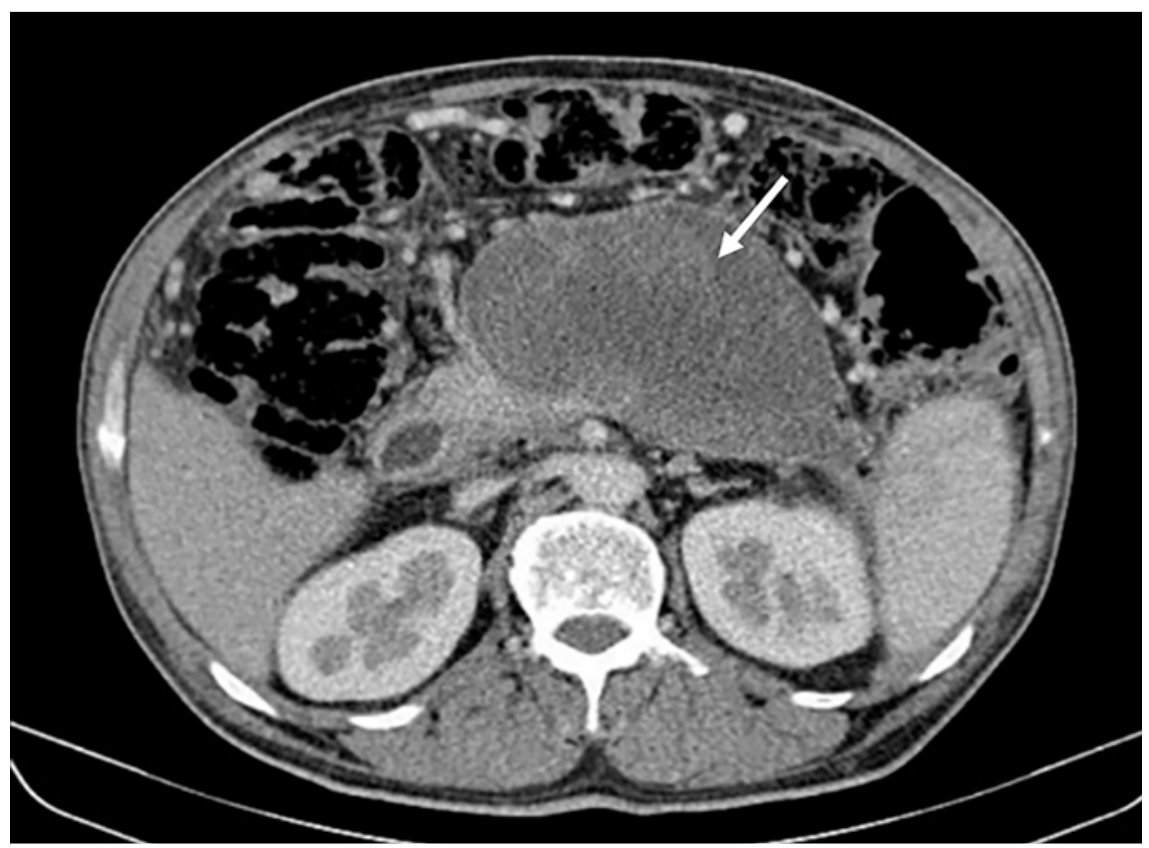

- Fig. 1 Abdominal computed tomography scan showing a well-defined cystic lesion (arrow), $16 \times 8 \mathrm{~cm}$ in diameter, in the tail of the pancreas. 


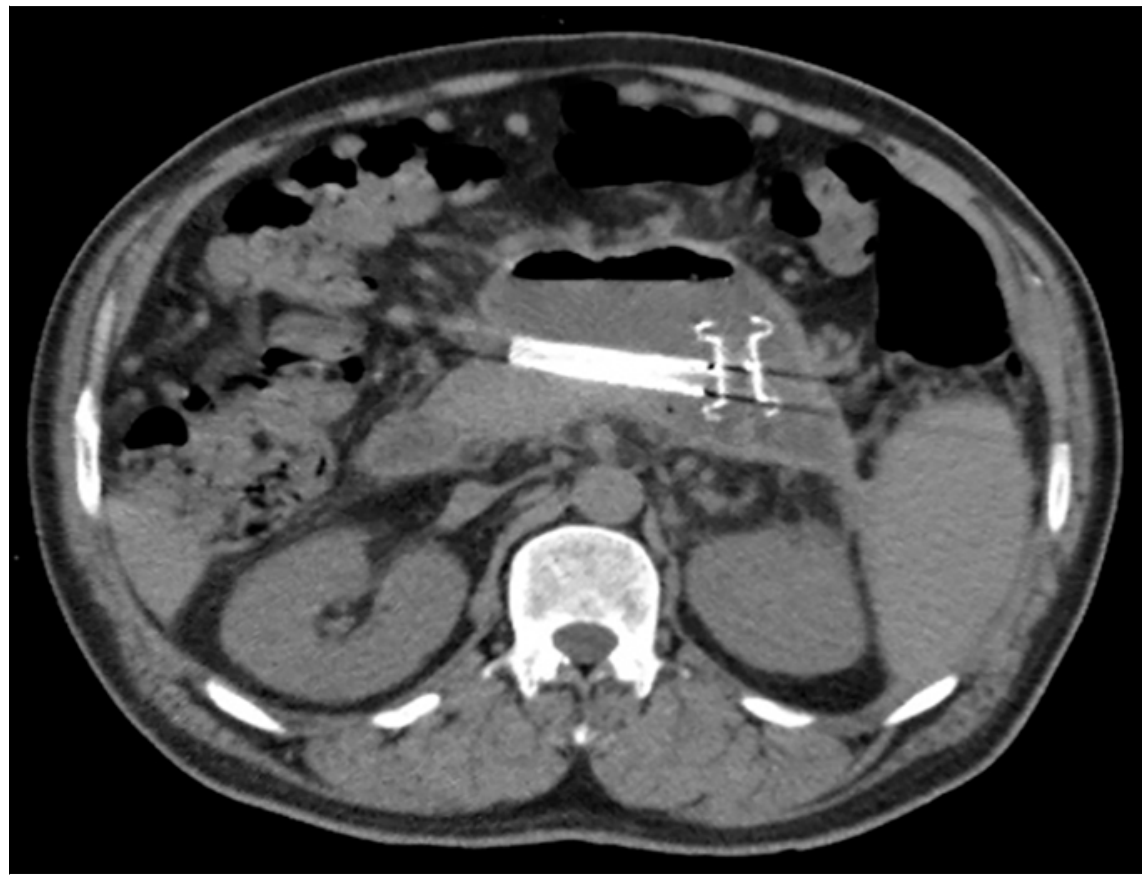

- Fig. 2 Abdominal computed tomography scan in axial view showing complete migration of the first two stents into the pseudocyst cavity.

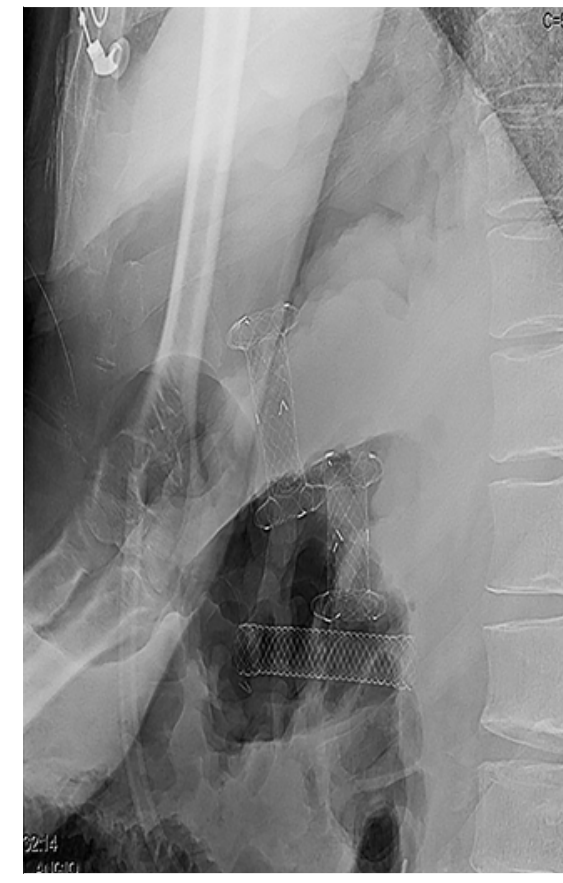

- Fig. 3 Fluoroscopic image showing the third stent through the cystogastrostomy and the first two stents in the pseudocyst cavity.
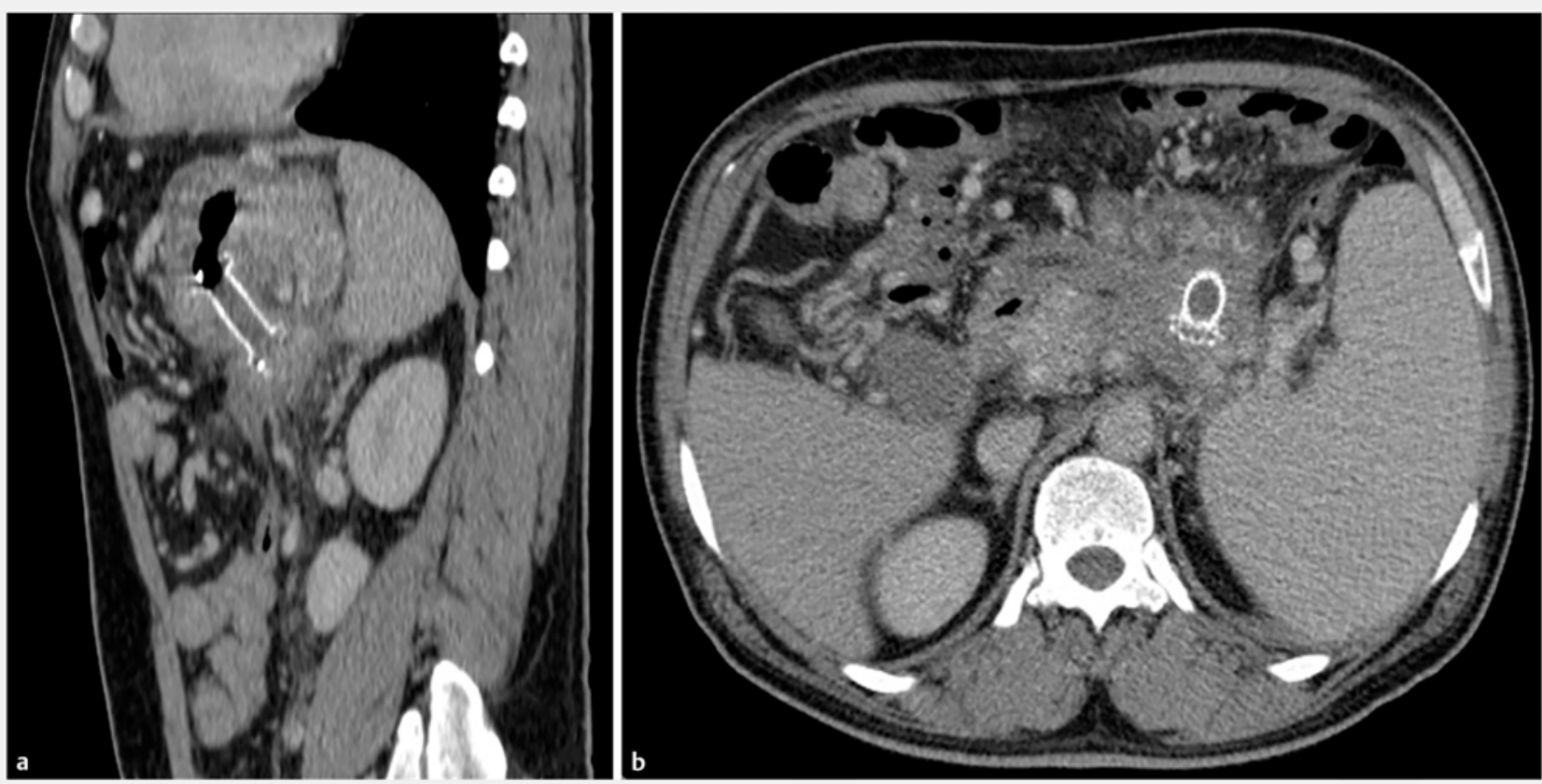

- Fig. 4 Abdominal computed tomography scan. a Coronal view, showing a correctly positioned fully covered double-flanged metal stent. b Axial view, showing complete resolution of the pancreatic pseudocyst. 


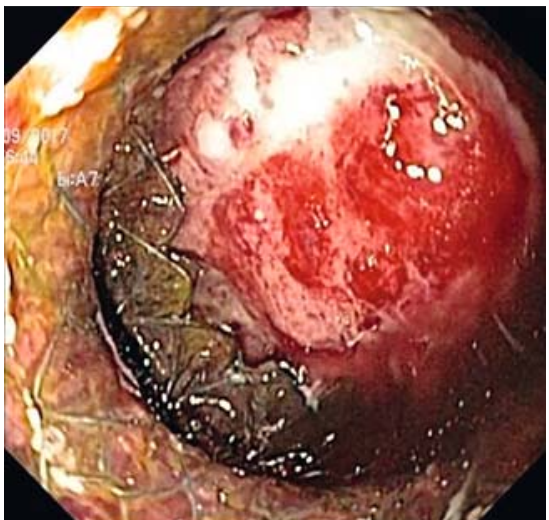

Fig. 5 Endoscopy image showing collapsed perigastric cavity consistent with complete resolution of the pseudocyst.

Intracystic stent migration is a rare (<1\%) complication of endoscopic drainage. It seems to be more frequent in transgastric drainage of pseudocysts of the pancreatic tail owing to variable luminal compression during the creation of cystogastrostomy [1].

We propose an alternative endoscopic method to solve intracystic stent migration, avoiding surgery [2].

Endoscopy_UCTN_Code_CPL_1AK_2AG
Competing interests

None

The authors

Juliana M. Costa ${ }^{1}$, Bruno M. Gonçalves ${ }^{1}$, Rita S. Costa ${ }^{1}$, Filipa Costeira ${ }^{2}$, Nuno Dias ${ }^{1}$, Raquel Gonçalves ${ }^{1}$, João B. Soares ${ }^{1}$

1 Department of Gastroenterology, Hospital de Braga, Braga, Portugal

2 Department of Radiology, Hospital de Braga, Braga, Portugal

\section{Corresponding author}

\section{Juliana M. Costa, MD}

Gastroenterology Department, Hospital de Braga, Sete Fontes - São Victor, 4710-243 Braga, Portugal Fax: +35-253-027999

julianamcosta87@gmail.com

\section{References}

[1] Varadarajulu S, Christein JD, Wilcox CM. Frequency of complications during EUS-guided drainage of pancreatic fluid collections in 148 consecutive patients. J Gastroenterol Hepatol 2011; 26: 1504-1508
[2] Wang GX, Liu X, Wang S et al. Stent displacement in endoscopic pancreatic pseudocyst drainage and endoscopic management. World J Gastroenterol 2015; 21 : $2249-2253$

\section{Bibliography}

DOI https://doi.org/10.1055/a-0655-1912

Published online: 8.8.2018

Endoscopy 2018; 50: E304-E306

(c) Georg Thieme Verlag KG

Stuttgart · New York

ISSN 0013-726X

\section{ENDOSCOPY E-VIDEOS \\ https://eref.thieme.de/e-videos}

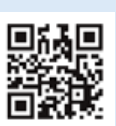

Endoscopy E-Videos is a free access online section, reporting on interesting cases and new

techniques in gastroenterological endoscopy. All papers include a high quality video and all contributions are freely accessible online.

This section has its own submission website at https://mc.manuscriptcentral.com/e-videos 